\title{
Peran Ayah Sebagai Pendidik Berdasarkan Efesus 6:4
}

\author{
Ezra Tari ${ }^{1}$, Maria Darniati Dimu², Nelman A. Weny³ \\ Institut Agama Kristen Negeri Kupang ${ }^{12}$, STT Methodis Medan ${ }^{3}$ \\ tariezra@gmail.com
}

\begin{abstract}
This article attempts to discover the role of the father in the family. Today's job demands make fathers rarely at home and involved in education. There are even children who live without a biological father. This paper describes the importance of the role of fathers in the family. The investigation uses a phenomenological approach. This approach seeks to see phenomena in the field. Research shows that the father is an essential figure in the family. Not only as a breadwinner. Fathers have a responsibility that is to have a positive impact on children's behaviour. Moreover, a father understands his role in educating children.
\end{abstract}

Keywords: Father, Education, Family, Ephesians

\begin{abstract}
Abstrak: Artikel ini berusaha menemukan peran ayah dalam keluarga. Tuntutan pekerjaan pada masa kini membuat ayah jarang di rumah dan terlibat dalam pendidikan. Bahkan ada anak yang hidup tanpa ayah kandung. Tulisan ini memaparkan pentingnya peran ayah dalam keluarga. Penyelidikan menggunakan pendekatan fenomenologi. Pendekatan ini berusaha melihat fenomena yang ada di lapangan. Penelitian menunjukkan bahwa ayah adalah sosok penting dalam keluarga. Bukan hanya sebagai pencari nafkah. Ayah memiliki tanggungjawab yakni memberi dampak positif terhadap perilaku anak. Dan seorang ayah memahami perannya dalam mendidik anak.
\end{abstract}

Kata Kunci: Ayah, Pendidik, Keluarga, Surat Efesus

\section{Article History : $\quad$ Received: 10 November 2020 Revised: 30 Desember 2020 Accepted:31 Desember 2020}

\section{Pendahuluan}

Kompleksnya masalah dalam rumah tangga menyebabkan banyak anak terpaksa harus ikut menanggung dampak negatif dari konflik yang terjadi. Persoalan perceraian orang tua, anak-anak harus berjuang mengatasi masalah. Karena salah satu dari pasangan suami istri bercerai entah ayah atau ibu terpaksa meninggalkan rumah dan hidup bersama dengan pasangan hidup yang baru. Anak yang orang tuanya menikah lagi, harus berusaha menyesuaikan diri dengan ayah atau ibu sambung dan saudara tirinya (kalau ada). Dan biasanya masa-masa penyesuaian ini penuh dengan ketegangan 
dan ketidakharmonisan. Ketika terjadi perceraian, biasanya yang diserahi tugas untuk mengasuh anak adalah ibu, namun ibu tidak dapat sepenuhnya mampu mengisi kokosongan peran ayah bagi anak-anaknya.

Harmaini, Vivik Shofiah, Alma Yulianti menerangkan ada bagian tiga besar yang dibuat oleh ayah dalam mengurus anak yakni; pertama, perlu rasa kasih sayang sebesar 36,7\%. Kedua, cara mengasuh 35,5 \%. Ketiga, dukungan keuangan 15,7\%. Dan 12\% faktor lain. ${ }^{1}$ Temuan terkait waktu yang dipakai ayah untuk mengadakan interaksi dengan anak adalah enam jam. Secara kuantitas, kesempatan ayah bersama anak sangat cukup untuk melaksanakan kegiatan bersama dengan anak. Sehingga saat hari libur, perlu dimaksimalkan untuk membangun kebersamaan dengan anak. ${ }^{2}$

Bagi penulis, ayah atau ibu yang kurang berperan dalam menjalankan fungsinya dapat dikategorikan sebagai tindakan kekerasan yang bersifat pembiaran. Ketika melakukan hal ini, kehadiran ayah atau ibu akan membawa dampak negatif bagi pertumbuhan psikologis anak. Dengan kata lain, membiarkan anak bertumbuh sendiri tanpa pendampingan yang benar dari pihak ayah dan ibu akan membawa pengaruh yang buruk bagi tumbuh kembang anak. Pendidikan dalam keluarga terus terkenang dalam ingatan anak-anak hingga mereka dewasa. Proses belajar yang terjadi di sekolah hanya dalam waktu singkat dan terjadwal, sedangkan anak lebih banyak di rumah sehingga orang tua memiliki kesempatan yang besar untuk memberikan dorongan, memberikan petunjuk, mengawasi dan memberikan jalan keluar terhadap masalah yang dihadapi oleh anak. ${ }^{3}$

Parmanti and Santi Esterlita Purnamasari menemukan peran KR dalam membina anak usia dini yakni, KR menemani anak bermain dengan membuat aneka mainan dari kertas seperti pesawat terbang dan kapal laut. KR menyerahkan kepada anak kebebasan bermain seperti; balok atau mobil-mobilan di dalam rumah dalam pengawasannya. ${ }^{4}$ Orang tua berperan penting dalam kehidupan anak dan remaja. Orang tua harus mengerti dan memahami peran dengan baik agar mampu membimbing remaja kepada jalan yang benar. ${ }^{5}$ Ketika anak masih balita, ayah dapat melakukan peran pendampingan

\footnotetext{
${ }^{1}$ Harmaini, Vivik Shofiah, and Alma Yulianti, “Peran Ayah Dalam Mendidik Anak," Jurnal Psikologi 10, no. 2 (2014), accessed July 27, 2020, https://media.neliti.com/media/publications/127544-ID-peranayah-dalam-mendidik-anak.pdf.

2 Farida Hidayati, Dian Veronika Sakti Kaloeti, and Karyono Karyono, "Peran Ayah Dalam Pengasuhan Anak," Jurnal Psikologi Undip 9, no. 1 (April 2011): 1-10.

${ }^{3}$ Ezra Tari and Talizaro Tafonao, "Pendidikan Anak Dalam Keluarga Berdasarkan Kolose 3:21," KURIOS (Jurnal Teologi dan Pendidikan Agama Kristen) 5, no. 1 (April ): 24-35.

4 Parmanti and Santi Esterlita Purnamasari, "Peran Ayah Dalam Pengasuhan Anak," Insight: Jurnal Ilmiah Psikologi 17, no. 2 (August 25, 2015): 81, accessed July 28, 2020, http://ejurnal.mercubuanayogya.ac.id/index.php/psikologi/article/view/687.

${ }^{5}$ Elsyana Nelce Wadi and Elisabet Selfina, "Peran Orang Tua Sebagai Keluarga Cyber Smart Dalam Mengajarkan Pendidikan Kristen Pada Remaja GKII Ebenhaeser Sentani Jayapura Papua," Jurnal Jaffray 14, no. 1 (2016), accessed July 28, 2020, https://media.neliti.com/media/publications/104562-peran-orangtua-sebagai-keluarga-cyber-s-05b7de71.pdf.
} 
dengan baik. ${ }^{6}$ Faktor penyebab ayah kurang perhatian kepada anak yakni; pertama, orang tua belum memahami kedudukan peran dan tanggung jawab dalam mendidik anak-anak di rumah. Kedua, kesadaran masyarakat yang lemah mengenai pentingnya pendidikan keluarga. Serta, tuntutan pemenuhan ekonomi keluarga.7 Padahal orangtua yang tamat SD, SMP, SMA dan perguruan tinggi acapkali memberikan pengalaman kepada anak. Waktu yang luang perlu orang tua berikan dalam memberi dukungan positif kepada anak. ${ }^{8}$ Cahyadi Takariawan menerangkan bahwa pendidikan dalam keluarga yang dimulai dengan baik sejak awal menjadi faktor penentu utama bagi bermutunya kehidupan anak di masa mendatang. ${ }^{9}$

Febri Giantara, Kusdani dna Santi Afrida menemukan peranan ayah dalam pendidikan keluarga di kota Pekanbaru berjalan dengan baik, terlihat pada peran sebagai pendidik, pelindung, pemberi rasa aman dan pendamping bagi anak-anak. ${ }^{10}$ Ayah dalam sebuah keluarga merupakan faktor yang sangat penting, menyangkut penataan yang baik dan tepat perkembangan fungsional sebuah rumah tangga. Ayah sebagai pendidik harus mampu mengenali ciri-ciri dasar anak, minat, temperamen dan khususnya karakter anak. ${ }^{11}$ Hasil penelitian memperlihatkan bahwa peran ayah berhubungan dengan adanya kehadiran ayah. ${ }^{12}$ Keterlibatan ayah masih terbatas pada pemenuhan kebutuhan ekonomi sedangkan waktu yang diluangkan untuk bersama anak masih terbatas karena tersita untuk mencari nafkah. ${ }^{13}$ Keterlibatan ayah dalam pola

6 T.R Wulan et al., "Ayah Tangguh, Keluarga Utuh : Pola Asuh Ayah Pada Keluarga Buruh Migran Perempuan Di Kabupaten Banyumas," Jurnal Ilmu Keluarga dan Konsumen 11, no. 2 (May 2018): 84-95, accessed July 30, 2020, http://journal.ipb.ac.id/index.php/jikk/article/download/19385/14957.

${ }^{7}$ M. Syahran Jailani, "Teori Pendidikan Keluarga Dan Tanggung Jawab Orang Tua Dalam Pendidikan Anak Usia Dini ," Nadwa: Jurnal Pendidikan Islam 8, no. 2 (October 2014), accessed July 31, 2020, https://journal.walisongo.ac.id/index.php/Nadwa/article/download/580/527.

8 Novrinda, Nina Kurniah, and Yulidesni, "Peran Orang Tua Dalam Pendidikan Anak Usia Dini Ditinjau Dari Latar Belakang Pendidikan," Jurnal Potensia 2, no. 1 (2017), accessed July 31, 2020, https://ejournal.unib.ac.id/index.php.

${ }^{9}$ Ernawati, "Konsep Pendidikan Rumah Tangga Dalam Perspektif Cahyadi Takariawan," SYAMIL: Jurnal Pendidikan Agama Islam (Journal of Islamic Education) 3 (2015).

${ }^{10}$ Febri Giantara, Kusdani, and Santi Afrida, "Peran Ayah Dalam Pendidikan Keluarga Di Kota Pekanbaru," JRPP: Jurnal Review Pendidikan dan Pengajaran 2, no. 2 (2019): 234-245, accessed August 13, 2020, https://journal.universitaspahlawan.ac.id/ind ex.php/jrpp/article/view/459.

${ }_{11}$ Ardita Ceka and Rabije Murati, "The Role of Parents in the Education of Children ," Journal of Education and Practice 7, no. 5 (2016), accessed August 11, 2020, www.iiste.org.

12 Siti Istiyati, Rosmita Nuzuliana, and Miftahush Shalihah, “Gambaran Peran Ayah Dalam Pengasuhan ," PROFESI (Profesional Islam): Media Publikasi Penelitian 17, no. 2 (March 1, 2020): 12-19, accessed January 7, 2021, https://journals.itspku.ac.id/index.php/profesi/article/view/22.

13 Beatriks Novianti Kiling-Bunga et al., "Persepsi Lurah Tentang Keterlibatan Agah Dalam Pengasuhan Dan Pendidikan Anak Usia Dini," JIV-Jurnal Ilmiah Visi 12, no. 1 (June 28, 2017): 9-18, accessed January 7, 2021, http://journal.unj.ac.id/unj/index.php/jiv/article/view/2799. 
asuh memberi dampak positif pada anak. Ia memberi warna tersendiri dalam pembentukan karakter anak. ${ }^{14}$

Berdasarkan penelitian di atas, penulis lebih memokuskan pada prinsip dan cara mengajar anak sesuai ajaran dan nasihat Tuhan. Penulis membangun pemikiran mengenai peran ayah sebagai pendidik berdasarkan Efesus 6:4.

\section{Metode Penelitian}

Pendekatan yang dipakai penulis adalah adalah studi pustaka. Penelitian studi pustaka memiliki ciri yakni: pertama, penulis atau peneliti meneliti secara langsung teks dan konteks. Kedua, kepustakaan. Di mana peneliti tidak terjun langsung ke lapangan. ${ }^{15}$ Serta memanfaatkan fenomena atau isu-isu kekinian yang sedang terjadi untuk dianalisis dalam rangka menghasilkan suatu temuan kompleks yang detail dan komprehensif. ${ }^{16}$ Studi pustaka memuat berbagai sumber yang diacu dan telah disajikan secara komprehensif serta membahas kesimpulan-kesimpulannya. ${ }^{17}$ Langkah kerja sutdi pustaka yakn; pertama, penulis menyiapkan perlengkapan. Kedua, membaca dan membuat catatan penelitian. ${ }^{18}$

\section{Hasil dan Pembahasan}

\section{Peran Ayah dalam Perjanjian Lama}

Allah memberikan tugas kepada orang tua untuk mendidik anak. Sehingga orang tua seyogyanya bertindak secara aktif dalam mendidik anak agar menjadi orang Kristen yang dewasa secara rohani. ${ }^{19}$ Dalam Perjanjian Lama penanaman nilai-nilai kebenaran bagi anak dikerjakan dalam berbagai cara. Allah secara langsung memberi perintah kepada Musa untuk menyampaikan segala ketetapan bagi bangsa Israel. ${ }^{20}$

${ }^{14}$ Suri Handayani Damanik, "Berdialog Dengan Ayah Sebagai Metode Stimulasi Perkembangan Kognitif Anak Usia Dini," Jurnal Bunga Rampai Usia Emas 2, no. 2 (December 1, 2016): 2502-7166, accessed January 7, 2021, https://jurnal.unimed.ac.id/2012/index.php/jhp/article/view/9422.

15 Supriyadi, "Community of Practitioners: Solusi Alternatif Berbagi Pengetahuan Antar Pustakawan," Lentera Pustaka 2, no. 2 (2016): 83-93, accessed July 13, 2020, https://ejournal.undip.ac.id/index.php/lpustaka/article/download/13476/10162.

16 Paul Cakra, "Beriman Secara Autentik: Memahami Allah Di Tengah Bencana Pandemi Covid-19," Sophia: Jurnal Teologi dan Pendidikan Kristen 1, no. 1 (June 2020), accessed July 17, 2020, http://sophia.iakn-toraja.ac.id/index.php/ojsdatasophia/article/view/5.

17 Perdy Karuru, "Pentingnya Kajian Pustaka Dalam Penelitian," Jurnal Keguruan dan Ilmu Pendidikan 2, no. 1 (2013): 1-9, accessed January 7, 2021, http://journals.ukitoraja.ac.id/index.php/jkip/article/view/149.

${ }^{18}$ Riskha Ramanda, Zarina Akbar, and R. A. Murti Kusuma Wirasti, "Studi Kepustakaan Mengenai Landasan Teori Body Image Bagi Perkembangan Remaja," JURNAL EDUKASI: Jurnal Bimbingan Konseling 5, no. 2 (December 31, 2019): 121, accessed January 7, 2021, https://jurnal.arraniry.ac.id/index.php/cobaBK/article/view/5019.

${ }^{19}$ Rut Ruat Diana, "Prinsip Teologi Kristen Pendidikan Orang Tua Terhadap Anak Di Era Revolusi Industri 4.0," BIA': Jurnal Teologi dan Pendidikan Kristen Kontekstual 2, no. 1 (June 24, 2019): 27-39, accessed April 14, 2020, http://www.jurnalbia.com/index.php/bia/article/view/79.

20 Maria Lidya Wenas and I Putu Ayub Darmawan, "Signifikansi Pendidikan Anak Dalam Perspektif Alkitab," Evangelikal: Jurnal Teologi Injili dan Pembinaan Warga Jemaat 1, no. 2 (July 2017), accessed August 3, 2020, http://journal.sttsimpson.ac.id/index.php/EJTI. 
Rumah merupakan tempat pembentukan anak-anak di Israel. Dalam tradisi Israel kuno, keluarga tidak hanya terdiri dari keluarga inti yakni: ayah, ibu, anak, melainkan keluarga besar yang disebut bet $a b$ (rumah bapa). ${ }^{21}$ Contoh seorang ayah yang gagal mendidik anaknya dalam Perjanjian Lama adalah Imam Eli (band. 1 Sam. 2: 11-36). Kegagalan imam Eli antara lain adalah penegakan disiplin dalam keluarga. Ia tidak tegas dalam mendisiplinkan anak-anaknya padahal masalah moralitas dan perilaku anak serta mengarahkan keluarga untuk senantiasa melakukan hal yang baik adalah tanggung jawab seorang ayah.

Anak adalah milik Tuhan yang dikaruniakan kepada ayah dan ibu. Maka seorang ayah wajib mengasuh, merawat, memelihara dan membesarkannya agar dapat tumbuh seimbang secara jasmani dan rohani. Mendidik anak-anak agar bermasa depan baik. Ayah harus bisa berperan sebagi guru. Pendidik yang memberi teladan. Sebagai pelindung dan motivator yang membuat anak berani dan percaya diri serta cerdas secara emosional. Sehingga ayah perlu terlibat dalam mengelola perkembangan sosialemosional anak sejak usia dini. ${ }^{22}$ Seorang Ayah tidak boleh membangkitkan amarah dalam hati anak-anak, namun mereka harus dididik agar mengenal hal-hal yang baik dan hal-hal yang tidak baik, sebab seorang bapak adalah pendidik utama dan pertama dalam keluarga. Mengajar anak agar takut kepada Tuhan dan menjauhi hal-hal yang negatif, misalnya mencuri.

Ayah sebagai sumber pengetahuan bagi anak, bukan hanya mentransfer pengetahuan untuk anak tetapi untuk menjawab rasa keingintahuan anak. Mendidik anak agar menjadi teladan. Sebagai pelindung dalam keluarga agar anak merasa nyaman secara emosi dan memiliki karakter yang baik. Pelindung bagi keluarga baik secara jasmani maupun rohani. Membuat anak menjad pemberani. Mendisiplinkan anak. Sebagai motivator agar anak lebih baik lagi. Membuat anak untuk memiliki rasa peduli pada orang lain. Senantiasa memberi perhatian dan mengawasi pergaulan anak.

Ada tiga peran yang hams diperankan dengan baik oleh orang tua, yaitu peransebagai penyelidik, petani dan arsitek. Peran orang tua sebagai penyelidik bertujuanuntuk menemukan apa yang tersembunyi atau belum diketahui. Peran orang tua disiniadalah mengenali diri, keunikan, talenta, bakat dan karakter anak agar orang tua dapat membimbing, mendorong, dan membantu perkembangan anak dengan

21 Yohanes Krismantyo Susanta, “Tradisi Pendidikan Iman Anak Dalam Perjanjian Lama," BIA': Jurnal Teologi dan Pendidikan Kristen Kontekstual 2, no. 2 (December 30, 2019): 139-150, accessed August 4, 2020, http://www.jurnalbia.com/index.php/bia.

${ }^{22}$ Ririn Hunafa Lestari and Syah Khalif Alam, "Mother's Perception of Father's Involvement in Developing Social-Emotional Development of Early Childhood" (Atlantis Press, 2020), 83-89, accessed August 3, 2020, https://www.atlantis-press.com/proceedings/icliqe-19/125933528. 
efektif. $^{23}$

Peran ayah adalah pelindung yang mempersiapkan anaknya untuk bisa melindungi dirinya sendiri karena orang tua tidak mungkin bersama anaknya setiap waktu. Ia sebagai partner yang aktif bagi ibu dalam hal mendidik anak. Ia memberi perhatian, mengawasi pergaulan anak, menjadi motivator. Sahabat bagi anak sehingga anak cerdas secara emosional dan mengajari anak menjadi mandiri serta memperkuat ikatan kekeluargaan. Ia mengawasi pergaulan anak dan memberi perhatian. Serta mengajar anak untuk memperkuat ikatan dalam sebuah keluarga. Menjadi sahabat bagi anak.

Hal yang timbul jika ayah gagal dalam melaksanakan tanggung jawabnya sebagai pendidik dalam keluarga. Anak akan kehilangan arah masa depannya (anak mengalami kebingungan). Anak tidak mendekatkan diri kepada Tuhan, berperilaku buruk dan terjerumus dalam pergaulan bebas. Anak tidak percaya diri, merasa tidak dihargai atau tidak dicintai sehingga anak bisa saja mengalami gangguan mental, depresi dan selalu merasa cemas. Anak mengalami masalah psikologis seperti gelisah, sedih, suasana hati selalu berubah-ubah, ketakutan dan frustrasi. Kemampuan anak cenderung berada di bawah rata-rata. Agresif dan membangkang terhadap orang tua.

Anak menjadi frustrasi, depresi, selalu menjadi penyebab keonaran, rasa percaya diri rendah, beresiko mengalami gangguan mental, suka membangkang, agresif, sulit dekat dengan orang lain. Rasa percaya diri anak menjadi rendah, mudah berbuat onar, depresi, agresif dan memiliki masalah kedekatan dengan orang lain. Ayah juga menjadi sosok yang sangat penting akan kehadirannya bagi seoranganak. Namun setiap ayah tidak lah sama, mereka memiliki pola pikir yang berbedaterhadap pengasuhan anak. ${ }^{24}$

Hasil penelitian hal-hal negatif yang dapat terjadi pada diri seorang anak yang yang tumbuh tanpa kehadiran seorang ayah karena ayah yakni: anak merasa tersisih dari orang tua/keluarga karena merasa tidak ada yang mempedulikannya, berpikir, bertindak/melakukan sendiri apa yang dipikirkannya, putus sekolah, menikah muda (khusus untuk anak perempuan) dan seks bebas. Singkatnya, anak cenderung berbuat hal-hal negatif yang merugikan orang lain, dirinya serta lingkungan. Anak kesulitan menyesuaikan diri di sekolah, lingkungan sosial. Sehingga terjadi perilaku sosial tidak wajar dan emosi tidak terkendali. Salah satu keterlibatan ayah yang paling banyak adalah perawatan tidak langsung. Hal ini berarti, Ayah berupaya mempersiapkan

${ }^{23}$ Vitaurus Hendra, "Peran Orang Tua Dalam Menerapkan Kasih Dan Disiplin Kepada Anak Usia 26 Tahun Sebagai Upaya Pembentukkan Karakter," Kurios: Jurnal Teologi dan Pendidikan Agama Kristen 3, no. 1 (October 2015): 48-65, accessed August 4, 2020, http://www.sttpb.ac.id/ejournal/index.php/kurios.

${ }^{24}$ Maisyarah, Anizar Ahmad, and Bahrun, "Peran Ayah Pada Pengasuhan Anak Usia Dini Dalam Keluarga Di Kecamatan Darussalam Kabupaten Aceh Besar," Jurnal Ilmiah Mahasiswa Pendidikan Guru Anak Usia Dini 2, no. 1 (May 2017): 50-61, accessed August 10, 2020, http://jim.unsyiah.ac.id. 
kebutuhan anak dan fasilitas pengembangan bakat dan minat anak. ${ }^{25}$

Seorang ayah perlu membangun komunnikasi yang baik dan membuka peluang bagi anak untuk dekat dengan kedua belah pihak, baik terhadap ibu maupun ayah. ${ }^{26}$ Sehingga komunikasi tidak berjalan dengan baik maka anak memiliki rasa percaya diri yang rendah karena kurangnya kasih sayang dari ayah dan ibu, anak menjadi terlantar, sulit dekat dengan orang lain. Anak tidak percaya diri, salah bergaul, tidak bertanggung jawab, beresiko mengalami gangguan mental dan fisik, dikucilkan, kehilangan kehormatan dan tidak memiliki masa depan yang bagus. Anak mudah depresi, tidak percaya diri, sulit berteman atau salah memilih teman, sulit bertanggung jawab, mudah curiga dan bisa saja mengalami gangguan mental. Menurut hasil pengamatan penulis, para ayah dari anak-anak yang mengalami fatherless justru merupakan ayah yang berpendidikan tinggi atau cukup berpendidikan, memiliki wawasan yang luas dan baik serta dari segi finansial cukup mampu membiayai atau memfasilitasi anak.

Ayah yang otoriter menyebabkan perubahan prilaku pada anak, umumnya anakmenjadi pesimis, minder, kurang percaya diri, malu karena tidak memiliki ayah lagi, nakal, minumobat-obatan terlarang atau melakukan tindakan kriminal lainnya. ${ }^{27}$ Kehadiran ayah pada sesi perawatan mungkin membantu mengurangi anggapan beban ibu dalam merawat anak mereka dengan penundaan dan membantu kedua orang tua fokus pada praktik dan meningkatkan teknik yang dipelajari selama pengobatan. ${ }^{28}$

Peran ayah menurut kitab Ulangan 6:1-9. Pertama, pentingnya penanaman nilainilai Kristiani di dalam setiap keluarga. Kedua, dalam menanamkan nilai-nilai Kristiani atau pengenalan akan Allah yang baik tersebut tidak bisa dilakukan oleh satu pihak dalam keluarga. Ketiga, seorang ayah juga memiliki peran yang besar untuk mendidik, mengajar dan menanamkan nilai-nilai Kristiani kepada anak-anak mereka. ${ }^{29}$ Penekanan yang digunakan dalam proses pendidikan adalah pada frasa "mengajarkannya berulang-

\footnotetext{
25 Wieka Dyah Partasari, Fransisca Rosa Mira Lentari, and Mohammad Adi Ganjar Priadi, “Gambaran Keterlibatan Ayah Dalam Pengasuhan Anak Usia Remaja (Usia 16-21 Tahun) ," Jurnal Psikogenesis 5, no. 2 (December 2017), accessed August 12, 2020, http://academicjournal.yarsi.ac.id/index.php.

${ }^{26}$ Cindy Widhiastuti and Maria Dwi Yanika Hesti Nugraha, "Peranan Stay At Home Dad Dalam Membentuk Keluarga Sehat Dan Harmonis," PSIBERNETIKA 6, no. 2 (October 2013), accessed August 10, 2020, https://journal.ubm.ac.id/index.php.

${ }^{27}$ Nurul Aini, "Probelmatika Anak Hidup Tanpa Ayah," in Seminar Nasional Gender \& Budaya Madura: Perempuan, Budaya \& Perubahan, 2016, accessed August 12, 2020, http://lppm.trunojoyo.ac.id/budayamadura/download.

${ }^{28}$ Daniel Bagner, "Father's Role in Parent Training for Children With Developmental Delay," Journal of family psychology: JFP : journal of the Division of Family Psychology of the American Psychological Association (Division 43) 27 (2013).

29 Tri Waluyo, "Peran Ayah Dalam Pendidikan Kepada Anak Menurut Ulangan 6:1-9," Jurnal Teologi El-Shadday 7, no. 1 (July 20, 2020): 36-56, accessed January 6, 2021, http://www.dpr.go.id/dokjdih/document/uu/UU_2002_23.pdf.
} 
ulang" sebagai metode dalam menyampaikan ajaran firman Tuhan kepada anak. ${ }^{30}$ Pola pengajaran dan pilih kasih dari ayah yang kurang baik berdampak buruk terhadap anak, misalnya kisah Ishak terhadap anak-anaknya (Kej.25:28). ${ }^{31}$ Seorang ayah harus bertanggung jawab terhadap tindakan anaknya, karena tongkat sebagai alat untuk mendisiplinkan anak tetapi seorang anak yang dibiarkan untuk dirinya sendiri mempermalukan ibunya (Ams. 29:15). ${ }^{32}$

\section{Efesus 6:4}

Seorang bapa hendaknya tidak menyakiti hati seorang anak (Ef. 6:4). Tanggung jawab ayah dalam mendidik anak tidak membuat anak merasa gusar. ${ }^{33}$ Ayah perlu memahami peran dalam membangun kedekatan dengan anak. ${ }^{34}$ Paulus memberikan nasehat mengenai kuasa seorang ayah yaitu kuasa yang dipunyai oleh seorang ayah bangsa Romawi terhadap keluarganya. ${ }^{35}$ Seorang Ayah harus membangun hubungan dengan anak sebab anak lebih banyak meniru. Apa yang dilihatnya akan ditirunya. Antara lain, anak kecil yang meniru Ayahnya, tetapi ia mengikuti cara-cara membentak orang, melihat ayahnya yang mengamuk. ${ }^{36}$

Sistem yang sudah terbentuk dalam keluarga memang sulit diubah. Istri terlihat mendidik sendiri sedangkan suami kurang terlibat dan tidak mendapat tempat. Hal ini tampak pada saat istri ragu-ragu dan khawatir suami kurang peduli. Ketika istri gelisah seperti ini, rasanya semua yang kurang tampak yaitu tanggung jawab dan pergaulan terhadap anggota keluarga. ${ }^{37}$ Untuk anak di bawah usia 5, penelitian menemukan bahwa 96\% dari ayah penduduk makan dengan mereka anak setiap hari atau beberapa kali minggu; 98\% bermain dengan anak-anak itu sering; 90\% mandi, memakai popok, atau

\footnotetext{
${ }^{30}$ Harls Evan Rianto Siahaan, "Hikmat Sebagai Implikasi Pendidikan Kristiani: Refleksi 1 Raja-Raja 3:1-15," DUNAMIS: Jurnal Penelitian Teologi dan Pendidikan Kristiani 1, no. 1 (October 1, 2016): 15-30, accessed January 6, 2021, https://www.sttintheos.ac.id/e-journal/index.php/dunamis/article/view/99.

31 Djoys Anneke Rantung, "Pendidikan Agama Kirsten Untuk Keluarga Menurut Pola Asuh Keluarga Ishak Dalam Perjanjian Lama," Jurnal Shanan 3, no. 2 (October 28, 2019): 63-76, accessed January 6, 2021, http://ejournal.uki.ac.id/index.php/shan/article/view/1579.

32 Juntao Zhao, View on Educational Thoughts in Old Testament, 2015, 828.

33 Magdalena P Santoso, "Pola Alkitabiah Pendidikan Anak 7-12 Tahun Yang Efektif Untuk Proses Pembentukan Karakter Pemimpin-Hamba Di Seminari Anak Pelangi Kristus,” Veritas 12, no. 1 (2011): 3960, accessed August 3, 2020, http://repository.seabs.ac.id.

${ }^{34}$ Bob Utley, Paulus Terbelenggu, Injil Tak Terbelenggu: Surat-Surat Dari Penjara (Kolose, Efesus Dan Filemon, Dan Kemudian, Filipi) (Marshall, Texas: Bible Lesson International, 2011), 187.

35 Elisa Elthon Tannu and Reymand Hutabarat, "Analisis Teologis Pemahaman Dan Penerapan Orang Tua Terhadap Makna Janganlah Bangkitkan Amarah Di Dalam Hati Anak-Anakmu Berdasarkan Efesus 6:4 Di Gereja Masehgi Advent Hari Ketujuh Jmeaat Palem Semi Dan Jemaat Makarios Kon Ferens DKI Jakarta," Jurnal Marturia 1, no. 1 (2017), accessed August 11, 2020, https://kti.unai.edu/index.php/martu/article/view/420.

${ }^{36}$ Marlin Sherly I.Y. Kawulur and Pujiati Gultom, "Dampak Didikan Orang Tua Kristen Terhadap Perilaku Anak Usia 6-9 Tahun Di GKKD Yogyakarta," Penabiblos VIII, no. 2 (November 2013), accessed August 11, 2020, http://www.e-jurnal.ukrimuniversity.ac.id.

37 Ramot Peter, “Peran Orangtua Dalam Krisis Remaja," Humaniora 6, no. 4 (2015): 453-460, accessed August 11, 2020, https://media.neliti.com/media/publications/167387-ID-peran-orangtuadalam-krisis-remaja.pdf.
} 
berpakaian

Anak-anak mereka setiap hari atau beberapa kali seminggu; dan 60\% membacakan untuk anak-anak mereka sesering itu. Untuk ayah yang tidak tinggal bersama anak-anak mereka, 30\% makan dengan mereka setiap hari atau beberapa kali minggu; 39\% bermain dengan anak-anak mereka beberapa kali seminggu atau lebih; $31 \%$ memandikan, mengganti popok, atau mendandani mereka anak-anak beberapa kali seminggu atau lebih. Dan 23\% membacakan untuk beberapa anak mereka kali seminggu atau lebih. ${ }^{38}$

Kemarahan itu termasuk sikap, perkataan, dan tindakan yang akan mendorong anak untuk marah atau kesal dan dengan demikian mengesampingkan disiplin yang terlalu keras, tuntutan yang tidak masuk akal, penyalahgunaan wewenang, kesewenangwenangan, ketidakadilan, omelan dan kecaman terus-menerus, menjadikan seorang anak dipermalukan, dan segala bentuk ketidakpekaan terhadap kebutuhan dan kepekaan anak. ${ }^{39}$ Dalam komunitas di mana ayah tidak hadir dan kurangnya figur ayah, kamp harus diorganisir. Di kamp-kamp ini, para pemimpin muda hendaknya diidentifikasi dan ayah dan ibu baru yang peka melalui kursus pelatihan yang relevan. Pelatihan yang dilakukan untuk ayah melalui lokakarya, road show, seminar, konferensi, dan pengayaan keluarga. Selain itu, penting bahwa remaja hendaknya dilatih melalui program menjadi ayah. ${ }^{40}$

Ayah perlu menjadi teladan di tengah keluarga baik dalam perkataan, pikiran dan perbuatan. Anak-anak adalah anugerah Tuhan dipercayakan kepada orang tua untuk taat dan menghormati orang tua. Dampaknya pada anak dari ketaatan dan rasa hormat kepada orang tua adalah janji Tuhan tentang kebahagiaan dan umur panjang. ${ }^{41}$ Bagi penulis, dalam Surat Efesus 6: 4, perhatian Rasul Paulus sedang difokuskan pada pendidikan kristiani dalam keluarga, terutama tentang tanggung jawab ayah sebagai pendidik pada masa itu, di mana pengaruh kehadiran ayah begitu kuat bagi proses tumbuh kembang anak. Paulus memberi nasihat berdasarkan kondisi yang terjadi pada waktu itu. Nasihatnya merupakan refleksi atas pengalamannya dalam konteks budaya di mana ia melayani. Persoalan tentang ayah sebagai pendidik dirasa perlu dan bersifat mendesak untuk disikapi. Rasul Paulus sedang berhadapan dengan kenyataan yang terjadi di mana para ayah pada waktu itu menyalah gunakan kewenangannya sebagai

\footnotetext{
38 Jo Jones and William D Mosher, "Fathers' Involvement With Their Children: United States, 2006-2010, "National Health Statistics Report 71, no. 1 (2006), accessed August 12, 2020, http://www.sas.com.

39 Johnson Rajendran, “An Exegesis on Household Code in Eph 6," n.d., accessed August 11, 2020, https://www.academia.edu/9092314/An_Exegesis_on_Household_code_in_Eph_6.

40 Fazel Ebrihiam Freeks, "Christian Fathers as Role Models of the Church's Fulfilment of the Missio Dei in a Fatherless Society," Missionalia 43, no. 3 (2018).

41 Dame Simamora, "The Role of Sunday School in Educating Children to Be Obedient and Faithful," 2020.
} 
ayah sehingga ayah tidak dapat memaksimalkan perannya yakni menjadi "berkat" bagi anak-anak mereka (para ayah lalai mendidik anak menurut Firman Tuhan). Ia melihat bahwa tugas sebagai seorang ayah terhadap anak-anak merupakan tugas/tanggung jawab yang sangat mulia dan bernilai. Keberhasilan seorang ayah dalam memaksimalkan perannya sebagai ayah Kristen dapat menghasilkan generasi yang tangguh, berprestasi serta dapat berpikir dan berperilaku baik. Rasul Paulus ingin menyadarkan para ayah pada masanya tentang hal tersebut agar para Ayah menyadari tanggung jawab mulia yang dipercayakan Tuhan kepada mereka yakni menjadi ayah yang senantiasa menciptakan suasana damai, nyaman dan penuh kasih sayang dalam keluarga, di mana Firman Tuhan (mengajarkan cinta kasih) menjadi inti dari bahan ajar yang memberi arah kepada seorang ayah dalam menjalankan tugas sebagai pendidik dalam keluarga.

Kualitas interaksi keluarga dari tahap paling awal kehidupan anak. Secara khusus, tingkat Keterlibatan Ayah yang lebih tinggi yang dilaporkan oleh orang tua sesuai dengan kompetensi interaktif keluarga yang lebih baik selama situasi permainan triadik. ${ }^{42}$ Pemberdayaan Orang Tua harus menjadi prioritas pemerintah. Jika orang tua tidak bekerja, itu tidak mungkin mereka untuk memenuhi kebutuhan anak-anak mereka, sehingga meninggalkan anak-anak untuk mengurus diri mereka sendiri, yang berkembang biak pengembaraan, mengemis jalanan dan kurangnya rasa hormat kepada orang tua mereka. Jelas bahwa setiap pemuda yang tidak menghormati orang tuanya akan sulit menghormati siapapun di luar.43

Ayah mempunyai tanggung jawab yang sangat berat. Karena ia harus menjaga kesehatan fisik serta perkembangan, secara keseluruhan perkembangan keluarga, Serta hubungan budaya yang kokoh dan berperilaku baik di keluarga itu sendiri serta dalam masyarakat tempat anak itu tinggal. ${ }^{44}$ Ayah yang terlibat dalam pengasuhan anak-anak memiliki kescerdasan moral dan emosi yang baik pada saat tumbuh dewasa. ${ }^{45}$

Penerapan disiplin terhadap anak termasuk di dalam rumah akan membentuk pribadi anak. ${ }^{46}$ Kerja sama dalam proses pembelajaran anak sangat penting agar dapat pencapaian tujuan. Orangtua memiliki harapan dan cita-cita yang tinggi terhadap anak

\footnotetext{
42 Alessandra Simonelli et al., "The Role of Father Involvement and Marital Satisfaction in the Development of Family Interactive Abilities: A Multilevel Approach," Frontiers in Psychology 7 (November 7, 2016): 1725, accessed August 12, 2020, http://journal.frontiersin.org/article/10.3389/fpsyg.2016.01725/full.

43 Theophilus Oludare Aliu, "Parental Role In Molding The Character Of Their Children," IOSR Journal Of Humanities And Social Science (IOSR-JHSS 7, no. 5 (2013), accessed August 11, 2020, www.Iosrjournals.Org.

${ }^{44}$ Ceka and Murati, "The Role of Parents in the Education of Children ."

45 Hasyim Asy'ari and Amarina Ariyanto, "Gambaran Keterlibatan Ayah Dalam Pengasuhan Anak (Paternal Involvement) Di Jabodetabek," Intuisi : Jurnal Psikologi Ilmiah 11, no. 1 (2019), https://journal.unnes.ac.id/nju/index.php/INTUISI/article/view/20115.

${ }^{46}$ M David, Daharnis Daharnis, and Azrul Said, "Persepsi Anak Terhadap Peran Ayah Dalam Keluarga Dan Implikasinya Terhadap Pelayanan Bimbingan Dan Konseling," Jurnal Konseling dan Pendidikan 2, no. 1 (March 2, 2014): 25, accessed August 12, 2020, http://jurnal.konselingindonesia.com.
} 
sehingga diperlukan kerja sama yang baik. ${ }^{47}$ Orang tua perlu menanam nilai karakter yang diberikan kepada anak yakni: pertama, latihan disiplin diri, ketekunan, tanggung jawab, rendah hati, bersikap sopan, jujur, dan tepat waktu. Kedua, orangtua dapat mendidik karakter anak meskipun belum berjalan secara maksimal. Namun orang tua perlu berupaya belajar meningkatkan kerja. Ketiga, perlu mengelola hambatan karena faktor lingkungan menjadi peluang. 48

Prinsip peran ayah sebagai pendidik yang dituntut oleh Efesus 6:4 adalah pertama, menasihati anak sesuai dengan perkembangannya (Ams.22:6a). Kedua, ayah tidak hanya memberi nasihat tetapi peri hidup (Ams.4:1-2, 29:7, 6:21). Ketiga, menegur anak dalam kasih (Ams. 13:24, 6:20). Keempat, ayah mendisiplin anak tepat pada waktunya (Ams. 13:24).

\section{Kesimpulan}

Ayah menjadi figur otoritas dalam budaya yang dianut pada masa pelayanan Rasul Paulus waktu itu. Rasul Paulus tentu berteori bukan di ruang hampa tetapi dari situasi/ konteks sosial dimana dia berada. Kontekslah yang menyebabkan Paulus menasehati dengan memberi penekanan pada ayah saja. Jadi, keluarga dibuat sebagai lembaga yang mendidik anak di mana ayah sebagai sokoguru dalam keluarga. Sebagai pendidik, Ayah memberikan tidak hanya sebatas memberi makanan, pakaian, mendoakan dan menasehati. Melainkan seorang ayah harus memahami dampak positif dari kehadiran ayah dan dampak negatif absennya ayah dalam keluarga. Dengan memiliki pemahaman yang lengkap mengenai tanggung jawabnya sebagai seorang ayah dalam memberi perhatian yang besar dan lebih bertanggung jawab dalam mendidik anak.

\section{Daftar Pustaka}

Aini, Nurul. "Probelmatika Anak Hidup Tanpa Ayah." In Seminar Nasional Gender \& Budaya Madura: Perempuan, Budaya \& Perubahan, 2016. Accessed August 12, 2020. http://lppm.trunojoyo.ac.id/budayamadura/download.

Asy'ari, Hasyim, and Amarina Ariyanto. "Gambaran Keterlibatan Ayah Dalam Pengasuhan Anak (Paternal Involvement) Di Jabodetabek." Intuisi : Jurnal Psikologi $\begin{array}{llll}\text { Ilmiah } & 11, & \text { no. } & \end{array}$ https://journal.unnes.ac.id/nju/index.php/INTUISI/article/view/20115.

\footnotetext{
${ }^{47}$ Nur Fadlin Amalia, "Pentingnya Kerjasama Orang Tua Untuk Membentuk Karakter Anak Di Dalam Keluarga," in Prosiding Seminas Nasional Psikologi Indigenous Indonesia, 2016, accessed August 12, 2020, http://digilib.mercubuana.ac.id/manager/t!@file_artikel_abstrak/Isi_Artikel_238136973184.pdf.

${ }^{48}$ Edi Widianto, "Peran Orangtua Dalam Meningkatkan Pendidikan Karakter Anak Usia Dini Dalam Keluarga," Jurnal PG-PAUD Trunojoyo : Jurnal Pendidikan dan Pembelajaran Anak Usia Dini 2, no. 1 (April 24, 2015): 31-39, accessed August 13, 2020, https://journal.trunojoyo.ac.id/pgpaudtrunojoyo/article/view/1817.
} 
Bagner, Daniel. "Father's Role in Parent Training for Children With Developmental Delay." Journal of family psychology: JFP: journal of the Division of Family Psychology of the American Psychological Association (Division 43) 27 (2013).

Cakra, Paul. "Beriman Secara Autentik: Memahami Allah Di Tengah Bencana Pandemi Covid-19." Sophia: Jurnal Teologi dan Pendidikan Kristen 1, no. 1 (June 2020). Accessed July 17, 2020. http://sophia.iakntoraja.ac.id/index.php/ojsdatasophia/article/view/5.

Ceka, Ardita, and Rabije Murati. "The Role of Parents in the Education of Children ." Journal of Education and Practice 7, no. 5 (2016). Accessed August 11, 2020. www.iiste.org.

Damanik, Suri Handayani. "Berdialog Dengan Ayah Sebagai Metode Stimulasi Perkembangan Kognitif Anak Usia Dini." Jurnal Bunga Rampai Usia Emas 2, no. 2 (December 1, 2016): 2502-7166. Accessed January 7, 2021. https://jurnal.unimed.ac.id/2012/index.php/jhp/article/view/9422.

David, M, Daharnis Daharnis, and Azrul Said. "Persepsi Anak Terhadap Peran Ayah Dalam Keluarga Dan Implikasinya Terhadap Pelayanan Bimbingan Dan Konseling." Jurnal Konseling dan Pendidikan 2, no. 1 (March 2, 2014): 25. Accessed August 12, 2020. http://jurnal.konselingindonesia.com.

Diana, Rut Ruat. "Prinsip Teologi Kristen Pendidikan Orang Tua Terhadap Anak Di Era Revolusi Industri 4.0." BIA': Jurnal Teologi dan Pendidikan Kristen Kontekstual 2, no. 1 (June 24, 2019): 27-39. Accessed April 14, 2020. http://www.jurnalbia.com/index.php/bia/article/view/79.

Ernawati. "Konsep Pendidikan Rumah Tangga Dalam Perspektif Cahyadi Takariawan." SYAMIL: Jurnal Pendidikan Agama Islam (Journal of Islamic Education) 3 (2015).

Fadlin Amalia, Nur. "Pentingnya Kerjasama Orang Tua Untuk Membentuk Karakter Anak Di Dalam Keluarga." In Prosiding Seminas Nasional Psikologi Indigenous Indonesia, 2016. Accessed August 2020. http://digilib.mercubuana.ac.id/manager/t!@file_artikel_abstrak/Isi_Artikel_2381 36973184.pdf.

Freeks, Fazel Ebrihiam. "Christian Fathers as Role Models of the Church's Fulfilment of the Missio Dei in a Fatherless Society." Missionalia 43, no. 3 (2018).

Giantara, Febri, Kusdani, and Santi Afrida. "Peran Ayah Dalam Pendidikan Keluarga Di Kota Pekanbaru." JRPP: Jurnal Review Pendidikan dan Pengajaran 2, no. 2 (2019): 234-245. Accessed August 2020. https://journal.universitaspahlawan.ac.id/index.php/jrpp/article/view/459.

Harmaini, Vivik Shofiah, and Alma Yulianti. "Peran Ayah Dalam Mendidik Anak." Jurnal Psikologi 10, no. 2 (2014). Accessed July 27, 2020. https://media.neliti.com/media/publications/127544-ID-peran-ayah-dalammendidik-anak.pdf.

Hendra, Vitaurus. "Peran Orang Tua Dalam Menerapkan Kasih Dan Disiplin Kepada Anak Usia 2-6 Tahun Sebagai Upaya Pembentukkan Karakter." Kurios: Jurnal Teologi dan Pendidikan Agama Kristen 3, no. 1 (October 2015): 48-65. Accessed August 4, 2020. http://www.sttpb.ac.id/e-journal/index.php/kurios. 
Hidayati, Farida, Dian Veronika Sakti Kaloeti, and Karyono Karyono. "Peran Ayah Dalam Pengasuhan Anak.” Jurnal Psikologi Undip 9, no. 1 (April 2011): 1-10.

Istiyati, Siti, Rosmita Nuzuliana, and Miftahush Shalihah. "Gambaran Peran Ayah Dalam Pengasuhan ." PROFESI (Profesional Islam): Media Publikasi Penelitian 17, no. 2 (March 1, 2020): 12-19. Accessed January 7, 2021. https://journals.itspku.ac.id/index.php/profesi/article/view/22.

Jailani, M. Syahran. “Teori Pendidikan Keluarga Dan Tanggung Jawab Orang Tua Dalam Pendidikan Anak Usia Dini ." Nadwa: Jurnal Pendidikan Islam 8, no. 2 (October 2014). Accessed July 31, 2020. https://journal.walisongo.ac.id/index.php/Nadwa/article/download/580/527.

Jones, Jo, and William D Mosher. "Fathers' Involvement With Their Children: United States, 2006-2010 ." National Health Statistics Report 71, no. 1 (2006). Accessed August 12, 2020. http://www.sas.com.

Karuru, Perdy. "Pentingnya Kajian Pustaka Dalam Penelitian." Jurnal Keguruan dan Ilmu Pendidikan 2, no. 1 (2013): 1-9. Accessed January 7, 2021. http://journals.ukitoraja.ac.id/index.php/jkip/article/view/149.

Kawulur, Marlin Sherly I.Y., and Pujiati Gultom. "Dampak Didikan Orang Tua Kristen Terhadap Perilaku Anak Usia 6-9 Tahun Di GKKD Yogyakarta." Penabiblos VIII, no. 2 (November 2013). Accessed August 11, 2020. http://www.ejurnal.ukrimuniversity.ac.id.

Kiling-Bunga, Beatriks Novianti, Yohana Krista Eka Tafuli, Friandry Windisany Thoomaszen, and Indra Yohanes Kiling. "Persepsi Lurah Tentang Keterlibatan Agah Dalam Pengasuhan Dan Pendidikan Anak Usia Dini." JIV-Jurnal Ilmiah Visi 12, no. 1 (June 28, 2017): 9-18. Accessed January 7, 2021. http://journal.unj.ac.id/unj/index.php/jiv/article/view/2799.

Lestari, Ririn Hunafa, and Syah Khalif Alam. "Mother's Perception of Father's Involvement in Developing Social-Emotional Development of Early Childhood." 8389. Atlantis Press, 2020. Accessed August 3, 2020. https://www.atlantispress.com/proceedings/icliqe-19/125933528.

Maisyarah, Anizar Ahmad, and Bahrun. "Peran Ayah Pada Pengasuhan Anak Usia Dini Dalam Keluarga Di Kecamatan Darussalam Kabupaten Aceh Besar." Jurnal Ilmiah Mahasiswa Pendidikan Guru Anak Usia Dini 2, no. 1 (May 2017): 50-61. Accessed August 10, 2020. http://jim.unsyiah.ac.id.

Novrinda, Nina Kurniah, and Yulidesni. "Peran Orang Tua Dalam Pendidikan Anak Usia Dini Ditinjau Dari Latar Belakang Pendidikan." Jurnal Potensia 2, no. 1 (2017). Accessed July 31, 2020. https://ejournal.unib.ac.id/index.php.

Oludare Aliu, Theophilus. "Parental Role In Molding The Character Of Their Children." IOSR Journal Of Humanities And Social Science (IOSR-JHSS 7, no. 5 (2013). Accessed August 11, 2020. www.Iosrjournals.Org.

Parmanti, and Santi Esterlita Purnamasari. "Peran Ayah Dalam Pengasuhan Anak." Insight: Jurnal Ilmiah Psikologi 17, no. 2 (August 25, 2015): 81. Accessed July 28, 
2020. yogya.ac.id/index.php/psikologi/article/view/687.

Partasari, Wieka Dyah, Fransisca Rosa Mira Lentari, and Mohammad Adi Ganjar Priadi. "Gambaran Keterlibatan Ayah Dalam Pengasuhan Anak Usia Remaja (Usia 16-21 Tahun) ." Jurnal Psikogenesis 5, no. 2 (December 2017). Accessed August 12, 2020. http://academicjournal.yarsi.ac.id/index.php.

Peter, Ramot. "Peran Orangtua Dalam Krisis Remaja." Humaniora 6, no. 4 (2015): 453460. Accessed August 11, 2020. https://media.neliti.com/media/publications/167387-ID-peran-orangtua-dalamkrisis-remaja.pdf.

Rajendran, Johnson. "An Exegesis on Household Code in Eph 6," n.d. Accessed August 11, 2020.

https://www.academia.edu/9092314/An_Exegesis_on_Household_code_in_Eph_6.

Ramanda, Riskha, Zarina Akbar, and R. A. Murti Kusuma Wirasti. "Studi Kepustakaan Mengenai Landasan Teori Body Image Bagi Perkembangan Remaja." JURNAL EDUKASI: Jurnal Bimbingan Konseling 5, no. 2 (December 31, 2019): 121. Accessed January $7,2021 . \quad$ https://jurnal.arraniry.ac.id/index.php/cobaBK/article/view/5019.

Rantung, Djoys Anneke. "Pendidikan Agama Kirsten Untuk Keluarga Menurut Pola Asuh Keluarga Ishak Dalam Perjanjian Lama." Jurnal Shanan 3, no. 2 (October 28, 2019): 63-76. Accessed January 6, 2021. http://ejournal.uki.ac.id/index.php/shan/article/view/1579.

Santoso, Magdalena P. "Pola Alkitabiah Pendidikan Anak 7-12 Tahun Yang Efektif Untuk Proses Pembentukan Karakter Pemimpin-Hamba Di Seminari Anak Pelangi Kristus." Veritas 12, no. 1 (2011): 39-60. Accessed August 3, 2020. http://repository.seabs.ac.id.

Siahaan, Harls Evan Rianto. "Hikmat Sebagai Implikasi Pendidikan Kristiani: Refleksi 1 Raja-Raja 3:1-15.” DUNAMIS: Jurnal Penelitian Teologi dan Pendidikan Kristiani 1, no. 1 (October 1, 2016): 15-30. Accessed January 6, 2021. https://www.sttintheos.ac.id/e-journal/index.php/dunamis/article/view/99.

Simamora, Dame. "The Role of Sunday School in Educating Children to Be Obedient and Faithful," 2020.

Simonelli, Alessandra, Micol Parolin, Chiara Sacchi, Francesca De Palo, and Alessio Vieno. "The Role of Father Involvement and Marital Satisfaction in the Development of Family Interactive Abilities: A Multilevel Approach." Frontiers in Psychology 7 (November 7, 2016): 1725. Accessed August 12, 2020. http://journal.frontiersin.org/article/10.3389/fpsyg.2016.01725/full.

Supriyadi. "Community of Practitioners: Solusi Alternatif Berbagi Pengetahuan Antar Pustakawan." Lentera Pustaka 2, no. 2 (2016): 83-93. Accessed July 13, 2020. https://ejournal.undip.ac.id/index.php/lpustaka/article/download/13476/10162.

Susanta, Yohanes Krismantyo. "Tradisi Pendidikan Iman Anak Dalam Perjanjian Lama." BIA': Jurnal Teologi dan Pendidikan Kristen Kontekstual 2, no. 2 (December 30, 2019): 
http://www.jurnalbia.com/index.php/bia.

Tannu, Elisa Elthon, and Reymand Hutabarat. "Analisis Teologis Pemahaman Dan Penerapan Orang Tua Terhadap Makna Janganlah Bangkitkan Amarah Di Dalam Hati Anak-Anakmu Berdasarkan Efesus 6:4 Di Gereja Masehgi Advent Hari Ketujuh Jmeaat Palem Semi Dan Jemaat Makarios Kon Ferens DKI Jakarta." Jurnal Marturia 1, no. 1 (2017). Accessed August 11, 2020. https://kti.unai.edu/index.php/martu/article/view/420.

Tari, Ezra, and Talizaro Tafonao. "Pendidikan Anak Dalam Keluarga Berdasarkan Kolose 3:21." KURIOS (Jurnal Teologi dan Pendidikan Agama Kristen) 5, no. 1 (April ): 2435.

Utley, Bob. Paulus Terbelenggu, Injil Tak Terbelenggu: Surat-Surat Dari Penjara (Kolose, Efesus Dan Filemon, Dan Kemudian, Filipi). Marshall, Texas: Bible Lesson International, 2011.

Wadi, Elsyana Nelce, and Elisabet Selfina. "Peran Orang Tua Sebagai Keluarga Cyber Smart Dalam Mengajarkan Pendidikan Kristen Pada Remaja GKII Ebenhaeser Sentani Jayapura Papua." Jurnal Jaffray 14, no. 1 (2016). Accessed July 28, 2020. https://media.neliti.com/media/publications/104562-peran-orang-tua-sebagaikeluarga-cyber-s-05b7de71.pdf.

Waluyo, Tri. "Peran Ayah Dalam Pendidikan Kepada Anak Menurut Ulangan 6:1-9." Jurnal Teologi El-Shadday 7, no. 1 (July 20, 2020): 36-56. Accessed January 6, 2021. http://www.dpr.go.id/dokjdih/document/uu/UU_2002_23.pdf.

Wenas, Maria Lidya, and I Putu Ayub Darmawan. "Signifikansi Pendidikan Anak Dalam Perspektif Alkitab." Evangelikal: Jurnal Teologi Injili dan Pembinaan Warga Jemaat 1, no. 2 (July 2017). Accessed August 3, 2020. http://journal.sttsimpson.ac.id/index.php/EJTI.

Widhiastuti, Cindy, and Maria Dwi Yanika Hesti Nugraha. "Peranan Stay At Home Dad Dalam Membentuk Keluarga Sehat Dan Harmonis." PSIBERNETIKA 6, no. 2 (October 2013). Accessed August 10, 2020. https://journal.ubm.ac.id/index.php.

Widianto, Edi. "Peran Orangtua Dalam Meningkatkan Pendidikan Karakter Anak Usia Dini Dalam Keluarga." Jurnal PG-PAUD Trunojoyo: Jurnal Pendidikan dan Pembelajaran Anak Usia Dini 2, no. 1 (April 24, 2015): 31-39. Accessed August 13, 2020. https://journal.trunojoyo.ac.id/pgpaudtrunojoyo/article/view/1817.

Wulan, T.R, Dalhar Shodiq, Sri Wijayanti, D.W.D Lestari, A.T Hapsari, Eri Wahyuningsih, and Hendri Restuadhi. "Ayah Tangguh, Keluarga Utuh: Pola Asuh Ayah Pada Keluarga Buruh Migran Perempuan Di Kabupaten Banyumas." Jurnal Ilmu Keluarga dan Konsumen 11, no. 2 (May 2018): 84-95. Accessed July 30, 2020. http://journal.ipb.ac.id/index.php/jikk/article/download/19385/14957.

Zhao, Juntao. View on Educational Thoughts in Old Testament, 2015. 